\title{
Applying e-Service Model in Assessment and Comparison of Services
}

\author{
Egidijus Ostasius and Zivile Petraviciute \\ Vilnius Gediminas Technical University, Department of Fundamental Sciences, \\ Sauletekio ave. 11, LT-10223 Vilnius, Lithuania \\ EgidijusOstasius@gama.vtu.lt, Zivile.Petraviciute@vgtu.lt
}

\begin{abstract}
The varying complexity, different maturity and rapid growth of the number of new e-services promote the assessment and their comparison with each other. This paper presents the application of e-service model in assessment and comparison of services in public sector. The model will assist the authorities to evaluate the maturity and complexity of the e-services they provide, and the systems that support these services. It could be helpful in comparing of eservices with other e-services provided by other authorities in the country and/or with other countries. The e-service model is based on the Reference Model for Service Oriented Architecture. A list of evaluation criteria that are based on the model is presented.
\end{abstract}

Keywords: e-government, e-service model, evaluation criteria, complexity, maturity.

\section{Introduction}

Aspirations of citizens, private sector, communities place new demands on governments for performance and efficiency and renewed focus on delivering better services. This forces trends towards reforming the public sector. It may move from traditional service delivery to the services in electronic domain or from the e-services in some sophistication (or maturity) level to the higher level. There is a need of measuring tools to show their respective areas of strengths and weaknesses with the egovernment readiness domain, to have possibilities for a comparative assessment of the e-services provided by the administrations or to transform their governments by using ICT to deliver e-services to their citizens and to monitor the advancement of governments in implementing e-government services.

Some studies with their methodologies of measuring sophistication level applied were conducted and they have ranked countries for e-government implementation. eEurope benchmarking [1] methodology essentially is based on online availability and ranking of e-services by the level of sophistication - five-stage maturity model: 1) Information: information necessary to start the procedure to obtain the service available on the web. 2) One way interaction: downloadable or printable form to start the procedure to obtain the service on the web. 3) Two-way interaction: electronic forms to start the procedure to obtain the service on the web. 4) Transaction: full electronic case handling of the procedure by the service provider. 5) Targetisation: 
proactive, automated service delivery. It was defined an initial set of 20 e-services and the existence and maturity levels of these services in EU member countries were assessed.

One of three main measures of the method of the UN study [2] - the Web Measure Index was based upon another five stage model of sophistication: 1) Emerging: a government's online presence is mainly comprised of a web page and/or an official website. 2) Enhanced: governments provide more information on public policy and governance. 3) Interactive: governments deliver online services such as downloadable forms. 4) Transactional: governments begin to transform themselves by introducing two-way interactions between 'citizen and government'. 5) Connected: governments transform themselves into a connected entity that responds to the needs of its citizens by developing an integrated back office infrastructure. This is the most sophisticated level of online e-government initiatives.

There were more methods and models presented (e.g. [3], [4], [5] and [6] - these methods are well discussed in [7]; [8]) that measure the sophistication level for eservices: they bear the basic features in common and are based on the stage models of sophistication. The stages in these models are not as distinct from each other as they need to be. The assessments using these methods are not sufficient: borders between stages are unclear and not distinguishable from each other on the criteria given in the model [7]. The new, more precise approaches and measures are needed for such an evaluation.

We suggest to evaluate and to separate e-services from each other in a more detailed way by seeking to identify the main aspects of the e-service characteristics. This paper provides an alternative model for e-service evaluation and presents an approach that could provide more comprehensive assessment for maturity and complexity of e-services and the systems that provide them. It also could fill the gap of the lack of self-evaluation methodology or comparison of e-service maturity, complexity in more detailed aspects for the purposes of the enhancement of e-services.

The presented evaluation model is based on evaluation criteria that are used to assess the sophistication level of e-service. Taking into consideration that the higher sophistication level means the higher maturity of the e-service the higher sophistication level causes the higher service level. Assuming that technology and service levels are intimately interwoven factors the complexity is higher when the service level is higher for the system that provides the e-service. Defining e-services as the result of automation, enhancement and integration of the business processes of the traditional services that are moving towards the e-services on demand [8] the higher service level means the more complex system providing the e-service. And contrary - the higher sophistication level means the simpler e-service from the user point of view (at least it should happen if the automation level is high enough). So the evaluation of the eservice maturity means also the evaluation of the system complexity.

\section{Constructing Evaluation Criteria}

The selection of the criteria was in accordance with the principles: 1) the importance and informativeness of the criteria, 2) the specific technological nature of the elements of e-services, and 3 ) the possibility to measure these criteria in practice. 
For the construction of the evaluation criteria we used different elements of service models that are important for the assessment in our context: the entities of Reference Model (RM) for Service-oriented Architecture [9], the service categorization according the model presented in the paper [7], and the elements of the e-service model [10] that is graphically presented in Fig. 1. We grouped the evaluation criteria in the hierarchical tree that represents a decomposition of attributes of criteria of different levels.

First group of attributes is related with the visibility of the e-service [9]. Visibility means that service provider and consumer to interact with each other they have to be able to "see" each other. One of the entities that visibility is based is awareness. Awareness means that both service provider and the service consumer must have information that would lead them to know of the other's existence. The information about the e-service may be presented as electronic description and policy including it in a service directory or broadcasting it to all service consumers. There must be sufficient information about the e-service and the method for the consumer to interact with the service in such a manner and form that a potential consumer is aware of existence and capabilities of the e-service. It is also desirable if an on-line demo version for the e-service is available where customers could look and test the e-service on their own before they use it. Another entity that visibility is based is reachability that means that service participants must be able to communicate with each other. If there is no communication between the consumer and provider then the service is not visible to the consumer and he/she cannot use it. As reachability means the possibility to communicate there are different options of means for the electronic communication. Most usable is public internet but there are more others communication means as well.

Second group of attributes is related with the identification of user (customer) of the e-service. Public services (C1) [7] are limited to services that need no identification of the users (customers) as they are publicly available to all citizens in a continuum of increasing interaction possibilities limited by the absent need for identifying the user (customer) in any degree at all. Services under this category do not involve the secure identification of the user (customer). Directed (or individualized) services (C2) are built up from services that need the user to be indirectly identified; it means that identification is carried out in automatic way using non-secured - semi personalized means for identification (e.g. e-mail address). Restricted services (C3) are based upon the need for a securely identified user in services that transfer information that is of no interest and that should not be accessible to people other than the user (customer) himself. This category requires secured means for user identification (e.g. eID) and has subcategories accordingly that are related with the option how customer identification is handled:

- outside information system (IS) initiation (SC1) means user identification outside the scope of information system: identification is carried out via the traditional signed document manually or in automatic way using electronic means of the third party;

- inside IS initiation (SC2) means user identification inside the scope of information system: identification is carried out in automatic way using secured - fully personalized means for identification. 


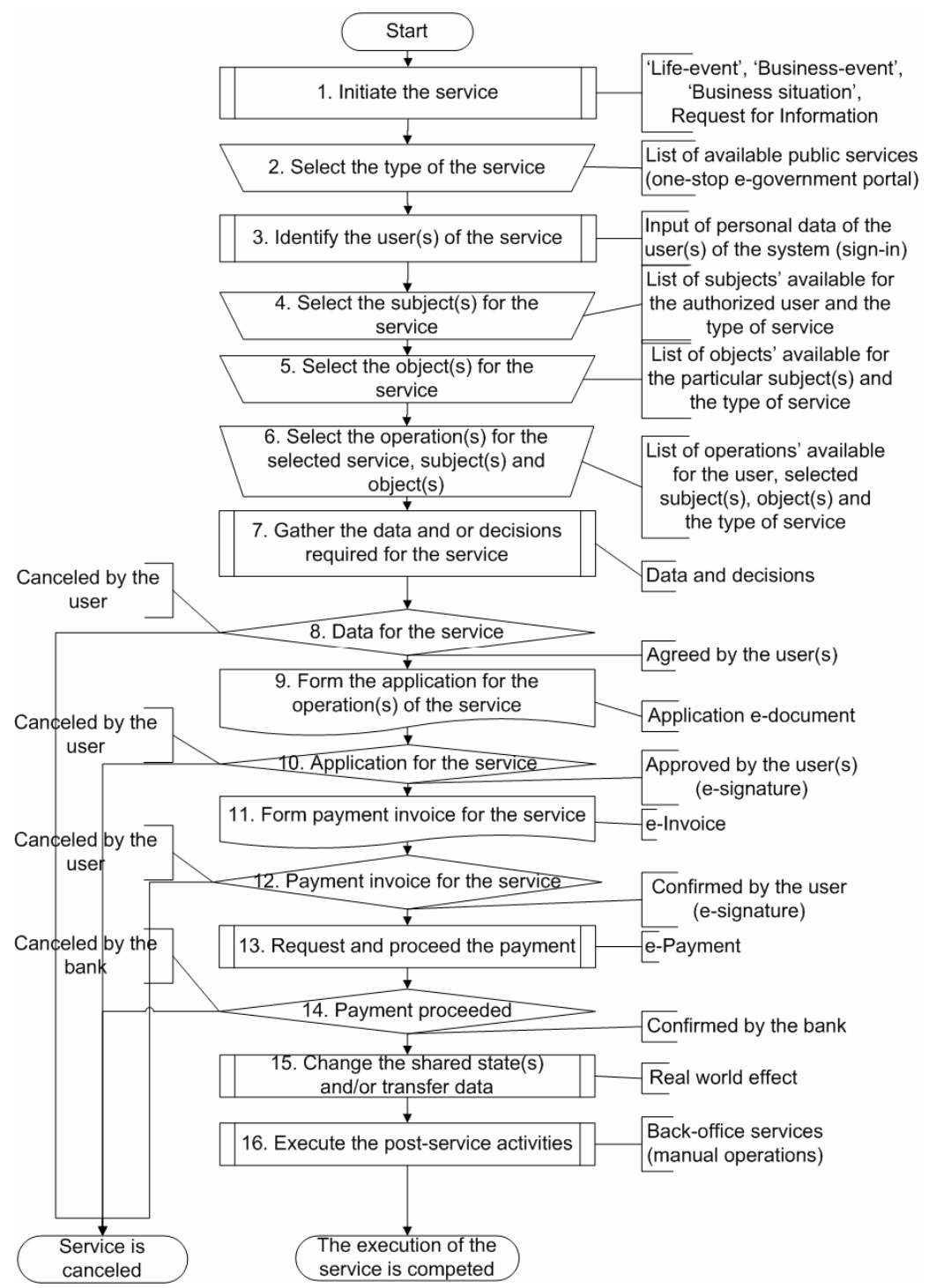

Fig. 1. E-service model [10]

User identification (Fig. 1, 3rd step) [10] starts from authentication activity where the identity of the person accessing services is executed and continues with authorization the activity that allows the access to the services that are conditioned by the individual's access level and his role. The user who will be using the services offered can possess one or a combination of the following roles: individual (user as the customer of the service), agent or organizational representative (user represents the customer).

Third group of attributes is related with the e-service case handling that means data collection (all the data that are required for the service should be collected) and decisions 
to be taken (internal approvals or rejections that are required for the service) (Fig. 1, 7th step) [10]. All the data if they are accessed electronically should be collected in automatic way. Other required data that cannot be accessed electronically or not available in electronic form should be entered manually. Next subcategories are related with this group. Manual case process (SC3) [7] means that handling and decision will be taken by a handling officer in the agency. Depending on the specific of data and the decision to be made it could be done in several ways: by the customer himself or entered by the agent or the organizational representative of the organization that provide the service or from the external organization according to the contents of the data sources - documents provided by the customer or organization. In all these cases the agent or the organizational representative has to approve electronically the certainty of the entered data that are based on the original documents that were presented or of the decisions that are based on obligations that the agent or the organizational representative possesses.

This subcategory may be characterized by next attributes:

1. The use of an interactive form in on-line processing. That means the user (customer) fills an electronic forms interactively.

2. The use of a non-interactive form. That means the electronic form can be downloaded, filled with data and uploaded or sent by the user (customer).

3. The electronic approval of data. It may be required in this case that data and/or decision must be approved by the user (customer) electronically.

Automated case process (SC4) means that data collection and/or the decisions in certain cases will be conducted in automatic way by programmed rules in an information system and no manual actions are needed for e-service case handling. The possibility of electronic notification allows monitor the progress of the e-service process.

Fourth group of attributes is related with the e-service document handling. After the data and/or decisions are collected and confirmed an electronic application (service contract) for the service may to be formed (Fig. 1, 9th step) [10]. It is optional depending on the specific of the service and is formed according to the selections, decisions and data collected. It is an option to use electronic document here or to add some attachments (e.g. documents, pictures) in electronic form to the application if it is necessary for the e-service. There may be other type of documents required that depend on the specific of the service in electronic or non-electronic form. Any electronic document may be authenticated by the user (customer) using electronic signature if it is required and if there are means for this action.

Fifth group of attributes is related with the payment handling. Direct payment for the e-service is optional and consists of two types: using internet banking or other electronic payment methods if such means are available (e.g. Credit/Debit cards).

Sixth group of attributes is an integration of services (C4) category that covers integration of government-to-government and other third party services for the eservice. This category has several subcategories.

1. Joint web production (SC5) subcategory bridges borders between government agencies and other organizations. In our case it covers common horizontal services such as electronic identification, electronic signature, electronic payment or other electronic services that are provided by other agencies and/or third parties.

2. Info or decision provision (SC6) required where an agency can be relying on input information or a decision from another agency or third party organization in order to be able to take a decision in a case relating the specific customer and/or 
service. The particular e-services may be controlled by one or several electronic restrictions that are originated in other agencies or third parties. There also may be an option for the electronic approval of the decisions from other agency or third party organization during the e-service procedure if it is necessary.

3. Database access (SC7) subcategory is needed for accessing a database in another agency or third party organization for receiving a piece of information needed for the e-service or decision to be taken in a certain case. There are options when the information is requested from registers or other electronic data sources.

4. Transparency in processes of several independent decisions (SC8) is when certain decisions need to be taken independently by several agencies or departments in order for the case process to be completed.

Seventh group of attributes covers post-service activities processes that are manual or not automated and they are needed for the completion of e-service process. The system may request for the human interaction to proceed some activities (e.g. logistics, printing certificates, non-electronic delivering of e-service results). It is optional when the completion of the e-service may be finalized by the automatic forming and electronic delivery of the e-service results: electronic certificates, electronic invoices or other results that can be delivered electronically if it is requested by the user (customer).

According to RM [9] the consequence of the service is a realization of one or more real world effects. These effects may include information returned in response to a request for that information or a change to the shared state of defined entities, or some combination of both. Real world effect means that the goal of the service consumer can often be expressed as 'trying to get the service to do something'. Eighth group of criteria covers the real world effect: return of the requested information and change of shared state of the defined entity of the e-service - object or subject.

Table 1. The hierarchical tree of criteria to be used for the e-service evaluation

\begin{tabular}{|c|c|}
\hline \multicolumn{2}{|l|}{ E-service evaluation criteria } \\
\hline 1- Visibility & Visibility of the e-service \\
\hline -- Awareness & Information about the e-service \\
\hline ---- e-Description & Electronic description and policy of the e-service \\
\hline ---- On-line demo & Existence of an on-line demo for the e-service \\
\hline -- Reachability & Means for communication \\
\hline ---- Internet & Public internet \\
\hline ---- Other means & Other communication means \\
\hline 2- E-service user & User of the e-service \\
\hline -- User identification & Identification of the user of e-service \\
\hline --- Public services & Need no identification of the user \\
\hline --- Directed services & Need the user to be identified indirectly \\
\hline ----- Semi personalized & Usability of not secured means for identification \\
\hline --- Restricted services & Need for a securely identified user \\
\hline ------ Outside IS initiation & Identification of the user outside the scope of IS \\
\hline ------ Inside IS initiation & Identification of the user inside the scope of IS \\
\hline -------- Fully personalized & Usability of secured means for identification \\
\hline -- User role & Possible option of user roles for the e-service \\
\hline --- Individual (customer) & Customer of the e-service \\
\hline --- Agent & Agent that represents the customer of the e-service \\
\hline --- Organizational representative & Organization that has obligation for customer e-service \\
\hline
\end{tabular}


Table 1. (continued)

\begin{tabular}{|c|c|}
\hline 3- Case handling & E-service process handling \\
\hline ---- Manual case processes & $\begin{array}{l}\text { Manual input of data and/or decision (human-to-system } \\
\text { interaction) }\end{array}$ \\
\hline ------ Interactive forms & Interactive on-line forms (info and decision) \\
\hline ----- Non-interactive forms & $\begin{array}{l}\text { Forms downloaded, filled and uploaded or sent by } \\
\text { e-mail (info and decision) }\end{array}$ \\
\hline ------ e-Approval & Internal approval of data and/or decision electronically \\
\hline ---- Automated case processes & Automatic case handling \\
\hline ---- e-Notification & Notification about the progress of the e-service \\
\hline 4- Document handling & Automatic handling of the document \\
\hline -- Application & An application for the service (service contract) \\
\hline ---- e-Application & Usability of electronic application \\
\hline ---- Attachments & Electronic documents can be attached \\
\hline -- Other documents & Other document for the service \\
\hline ---- e-Document & Usability of other electronic document \\
\hline -- e-Authentication & Electronic authentication of the document \\
\hline 5- E-payment & Electronic payment of service \\
\hline -- Internet banking & Direct e-Payment through internet banking \\
\hline -- Other e-Payment method & Direct e-Payment through other means \\
\hline 6- Integration of services & $\begin{array}{l}\text { Integration of services and agencies (system-to-system } \\
\text { interaction) }\end{array}$ \\
\hline ---- Joint information services & Joint web production \\
\hline ------ e-Identification & Electronic identification service through third party \\
\hline ------ e-Signature & Electronic signature service through third party \\
\hline ------ e-Payment & Electronic payment service through third party \\
\hline ------ Other e-service & Other electronic service through third party \\
\hline ---- Info or decision & External info or decision provision required \\
\hline ------ e-Restriction & Electronic restriction of e-service \\
\hline ------ e-Approval of decision & External electronic approval of e-service \\
\hline ---- Database access & Database access in information gathering \\
\hline ------ Registers & Electronic data exchange with registers \\
\hline $\begin{array}{l}\text {----- Other electronic data } \\
\text { sources }\end{array}$ & Electronic data exchange with other data sources \\
\hline ---- Transparency & $\begin{array}{l}\text { Transparency in processes of several independent } \\
\text { decisions }\end{array}$ \\
\hline 7- Post-service activities & E-service completion activities \\
\hline $\begin{array}{l}\text {-- Manual or not automated } \\
\text { processes }\end{array}$ & Not automated activities \\
\hline ---- e-Request & $\begin{array}{l}\text { Request for human interaction (system-to-human } \\
\text { interaction) }\end{array}$ \\
\hline -- e-Delivery & Electronic delivery of e-service results \\
\hline ---- e-Certificate & Electronic certificate can be formed and downloaded \\
\hline ---- e-Invoice & Electronic invoice can be formed and downloaded \\
\hline ---- Other results e-delivery & Electronic delivery of other results of e-service \\
\hline 8- Real world effect & Consequence of invoking the e-service \\
\hline ---- Information return & Response to the request for that information \\
\hline ---- Change of shared state & A change of shared state of defined entity \\
\hline
\end{tabular}




\section{Conclusions and Future Work}

We constructed and presented the list of evaluation criteria for e-service assessment and comparison in this paper. The basis for criteria construction was Reference Model (RM) for Service-oriented Architecture [9], the models presented in the papers [5] and [10]. The evaluation criteria can be used for self-evaluation benchmarking of eservices, in assessment and comparison of different e-services in a country or in different countries, or in assessment and comparison of the same type of e-services in different countries. The e-service assessment as a tool could promote development of the governance of the virtual enterprise - collaborative e-government.

Future works that are planned are focused on the validation of presented criteria in practical testing on real existing e-services and the systems that provide these services.

\section{References}

1. Smarter, Faster, Better eGovernment. 8th eGovernment Benchmark Measurement (2009), http://ec.europa.eu/information_society/eeurope/i2010/docs/b enchmarking/egov_benchmark_2009.pdf

2. E-Government Survey, United Nations (2008), http://www2.unpan.org/ egovkb/global_reports/10report.htm\#sa

3. Electronic Service Delivery, including Internet use by Commonwealth Government Agencies, Australian National Auditing Office, Canberra, Australia (1999)

4. The 24/7 Agency: Criteria for 24/7 Agencies in the Networked Public Administration, Statskontoret 2000:41, Sweden (2000)

5. Layne, K., Lee, J.: Developing fully functional E-government: A four stage model. Government Information Quarterly 18, 122-136 (2001)

6. Hiller, J., Belanger, F.: Privacy strategies for electronic government. PricewaterhouseCoopers, Arlington (2001)

7. Persson, A., Goldkuhl, G.: Stage-models for public e-services - investigating conceptual foundations. Accepted to the 2nd Scandinavian Workshop on e-Government, Copenhagen (2005)

8. IBM Business Consulting Services. How e-government are you? e-government in France: State of play and perspectives (2003), http://www-935.ibm.com/services/ id/igs/pdf/g510-3552-00-esr-e-government.pdf

9. Reference Model for SOA, Version 1.0, OASIS Standard (2006), http://docs. oasis-open.org/soa-rm/v1.0/soa-rm.pdf

10. Ostasius, E., Petraviciute, Z.: Modeling e-services in public sector - INFORMACIJOS MOKSLAI (to be published in 2010), http://www. leidykla.eu/en/journals/information-sciences/, http://e-stud.vgtu.1t/files/dest/13822/im2010.pdf 